\title{
Narrativas de estagiários de enfermagem sobre a criança hospitalizada como sujeito de direitos
}

\author{
Narratives of nursing trainees about the hospitalized child as a subject of rights \\ Narraciones de aprendices de enfermería sobre el niño hospitalizado como sujeto de derechos
}

\begin{abstract}
RESUMO
Embora a criança tenha direitos legalmente assegurados de se expressar sobre o que lhe diz respeito, ela enfrenta obstáculos para exercê-los pela ausência do reconhecimento desses direitos. Objetivo: Discutir resultados da pesquisa sobre os modos como futuros profissionais de enfermagem percebem, em suas narrativas, os direitos da criança hospitalizada Métodos: Entrevistas narrativa, realizadas no período de 09/2020 à 03/2021, com três estagiários do curso Técnico de Enfermagem e três estagiários de Enfermagem, de instituições de ensino de São Paulo. Resultados: As análises revelam a invisibilidade da criança como sujeito de direitos por parte dos entrevistados, futuros profissionais de enfermagem. Conclusões: Admite-se que os cursos de formação em Enfermagem ganhariam em proporcionar ao futuro profissional uma postura mais reflexiva e autopoiética sobre a compreensão da agentividade da criança de modo a melhor orientar habilidades e atitudes mais humanizadas nas práticas de acolhimento à criança hospitalizada.
\end{abstract}

DESCRITORES: Criança Hospitalizada; Direitos da Criança; Educação em Enfermagem.

\section{ABSTRACT}

Although children have legally guaranteed rights to express themselves about what concerns them, they face obstacles to exercising them due to the lack of recognition of these rights. Objective: To discuss the results of the research on the ways in which future nursing professionals perceive, in their narratives, the rights of hospitalized children. Methods: Narrative interviews, carried out from 09/2020 to 03/2021, with three trainees of the Technical Nursing course and three Nursing trainees, from teaching institutions in São Paulo. Results: The analyzes reveal the invisibility of the child as a subject of rights by the interviewees, who are future nursing professionals. Conclusions: It is admitted that nursing education courses would benefit from providing future professionals with a more reflective and autopoietic posture on the understanding of the child's agentivity in order to better guide more humanized skills and attitudes in the practices of welcoming hospitalized children.

DESCRIPTORS: Hospitalized Child; Children's Rights; Nursing Education.

\section{RESUMEN}

Aunque los niños tienen derechos legalmente garantizados para expresarse sobre lo que les concierne, se enfrentan a obstáculos para ejercerlos debido a la falta de reconocimiento de estos derechos. Objetivo: Discutir los resultados de la investigación sobre los modos en que los futuros profesionales de la enfermería perciben, en sus narrativas, los derechos de los niños hospitalizados. Métodos: Entrevistas narrativas, realizadas entre 09/2020 y 03/2021, con tres pasantes del Curso Técnico de Enfermería y tres pasantes de Enfermería, de instituciones de enseñanza de São Paulo. Resultados: Los análisis revelan la invisibilidad del niño como sujeto de derechos por parte de los entrevistados, futuros profesionales de la enfermería. Conclusiones: Se admite que los cursos de formación de enfermería se beneficiarían de dotar a los futuros profesionales de una postura más reflexiva y autopoiética sobre la comprensión de la agentividad del niño para orientar mejor las habilidades y actitudes más humanizadas en las prácticas de acogida de los niños hospitalizados.

DESCRIPTORES: Niño hospitalizado Derechos de los niños, Enseñanza de la enfermeira.

RECEBIDO EM: 29/06/2021 APROVADO EM: 27/07/2021 


\section{MARIA CLAUDIA TEIXEIRA DE MACEDO SILVA}

Enfermeira. Discente no Programa de Pós Graduação Mestrado Acadêmico em Educação - Universidade Cidade de São Paulo. Bacharel em Enfermagem. Especialista em Saúde Mental e Psiquiátrica, Especialista em Docência no Ensino Médio, Técnico e Superior na área da Saúde, Especialista em Enfermagem do Trabalho, Especialista em Educação Continuada e Permanente em Saúde.

ORCID: 0000-0002-3359-3557

\section{DRA. MARIA DA CONCEIÇÃO PASSEGGI}

Pesquisadora produtividade CNPq - Pq1-D. Doutora em Linguística com Pós-doutorado em Fundamentos da Educação. Professora dos Programas de Pós-Graduação em Educação da Universidade Cidade de São Paulo e da Universidade Federal do Rio Grande do Norte. Coordenadora do GRIFARS-UFRN-CNPq. Pesquisadora associada do CIEP-FCT, Universidade de Évora, do CIEC-FCT, Universidade do Minho, do Laboratoire EXPERICE, Université de Paris Sorbonne Cité e do CIERS-Ed, Fundação Carlos Chagas.

ORCID: 0000-0002-4214-7700

\section{INTRODUÇÃO}

m meados do século XX, surgem os primeiros marcos legais relativos aos direitos das crianças. ${ }^{1}$ Com a promulgação da Constituição Federal Brasileira em 1988, houve a inclusão do artigo 227, específico sobre os direitos das crianças, enfatizando o direito a saúde. Consequentemente, a Constituição Federal favoreceu a criação do Estatuto da Criança e do Adolescente (ECA) em 1990, garantindo os direitos prescritos na Lei $\mathrm{n}^{\circ} 8.069$ de 13 de julho de $1990{ }^{2}$

A partir dos anos 90 multiplicam-se as contribuições científicas, notadamente da Sociologia da infância, na direção de consolidar seu estatuto como sujeito de direitos, assegurando-lhes a possibilidade de se expressarem livremente em assuntos que lhes dizes respeito.

Tais conquistas se opõem à percepção usual da palavra da criança, tradicionalmente ignorada por ser considerada imatura, logo, difícil de ser reconhecida no universo dos adultos ${ }^{3}$. No momento atual, já não se pode desconhecer que as crianças produzem modos próprios de se inserirem nos contextos socioculturais em que vivem, o que as tornam agentes sociais, ativos e criativos ${ }^{4}$, razões pelas quais torna-se cada vez mais premente a importância de escutá-las para compreender como enfrentam problemas e crises por elas experienciados. A ausência desse reconhecimento contribui para a exclusão da palavra da criança nos processos de socialização, escolarização e hospitalização.
A hospitalização, que nos interessa particularmente aqui, é causa de angústias e incertezas para qualquer pessoa, mas, quando se trata de uma criança, além de envolver esses sentimentos é possível observar seu desconforto para enfrentar os desafios das mudanças provocadas pela hospitalização e o isolamento social. Por tais razões, no que se refere aos cuidados por profissionais de saúde se faz cada vez mais necessário que se atente para a singularidade de cada criança no que diz respeito a aspectos psicológicos, sociais e atitudinais.

A enfermagem é uma profissão em que o cuidado se constitui numa de suas mais marcantes características, o que exige uma elevada capacidade empática desse profissional de saúde no sentido de saber se colocar no lugar da pessoa em tratamento, visando uma assistência mais humanizada como parte do serviço de atendimento no enfrentamento à hospitalização. ${ }^{67}$ Considera-se que o cuidado pauta-se em três pilares: a boa relação profissional-paciente; um ambiente laboral acolhedor e a disponibilização de informações hospitalares precisas sobre cada paciente de modo que o tratamento respeite sua singularidade como um direito à saúde. 5

Trata-se de saber em que medida a criança hospitalizada enfrenta obstáculos para ser reconhecida como sujeito de direitos pelos profissionais de enfermagem. ${ }^{6}$ Essa é uma das questões que norteia as pesquisas que desenvolvemos sobre a formação de estagiários de enfermagem - enfermeiros e técnicos de enfermagem - com foco no atendimento de crianças hospitalizadas.
As instituições de ensino estão preparando devidamente esses futuros profissionais de forma a que compreendam a criança hospitalizada como sujeito de direitos, ativo, criativo e produtor de cultura? Nosso objetivo neste artigo é discutir resultados da pesquisa sobre os modos como futuros profissionais de enfermagem percebem a importância dos direitos da criança hospitalizada.

\section{MÉTODO}

Trata-se de uma pesquisa qualitativa que utiliza como instrumento de investigação a entrevista narrativa. ${ }^{8} \mathrm{O}$ referencial teórico, está pautado no campo da sociologia da infância ${ }^{3}{ }^{4}$ da pesquisa (auto)biográfica com crianças e sobre seu acolhimento nos serviços de saúde. 9 , 10

O corpus está constituído por entrevistas realizadas com 3 (três) alunos do Curso Técnico de Enfermagem de uma mesma instituição de ensino, localizada em São Paulo, e com 3 (três) alunos do Curso de Graduação em Enfermagem de diferentes universidades de São Paulo. Como critério de seleção dos participantes, foi considerado que tivessem concluído a disciplina correspondente à saúde da criança, no âmbito teórico, teórico-prático e ter realizado o estágio supervisionado. Devido à situação de isolamento social, face à pandemia por Covid-19, as entrevistas foram realizadas por meio da plataforma digital Google Meet, com duração de 50 minutos, num único encontro, com cada participante. A coleta de dados ocorreu entre setembro de 2020 e março de 2021. 
De acordo com a Resolução CNS $466 / 12$, o trabalho foi aprovado pelo Comitê de Ética em Pesquisa da Universidade Cidade de São Paulo e o consentimento dos participantes mediante assinatura do Termo de Consentimento Livre e Esclarecido. Para respeitar o anonimato dos participantes, os próprios entrevistados escolheram como pseudônimos nomes de super-heróis.

As análises dos dados focalizam as experiências tematizadas pelos estagiários e visam depreender a percepção que eles têm da criança hospitalizada como sujeito de direitos, assim como a forma como ressignificam a compreensão de si no próprio ato de narrar, fazendo com que a narrativa se transforme num processo autopoiético. ${ }^{11}$ Considerando que a Enfermagem está pautada no cuidado, na empatia e na boa relação entre paciente e profissional ${ }^{7}$, ainda é possível observar que futuros profissionais apresentam dificuldades de conceber a criança hospitalizada como sujeito de direitos e o reconhecimento de seu direito à livre expressão.

\section{RESULTADOS}

A pesquisa com os estagiários partiu do pressuposto segundo o qual o ato de narrar a experiência vivida tem o poder de gerar uma maior compreensão da vida por permitir a quem narra dar sentido ao vivido. ${ }^{12}$ Assim, possibilitar a estagiários de enfermagem momentos de reflexão sobre sua própria experiência se justifica pelo próprio benefício de ajudá-los a compreender a si mesmos, seu processo de formação e desenvolver uma percepção crítica sobre possíveis lacunas, êxitos e perspectivas em curso. A conversa com os estagiários de enfermagem iniciou-se sobre o conhecimento que tinham sobre os direitos da criança hospitalizada. Retomamos abaixo excertos escolhidos que nos parecem significativos de seus modos de entender os direitos da criança hospitalizada.

É possível observar a importância atribuída ao acolhimento da criança em seu período de hospitalização e a empatia do profissional, de forma a minimizar os impactos causados pela hospitalização e as bruscas rupturas na vida cotidiana.

Para Naruto e Gamora, ambos estagiários do Técnico de Enfermagem, o respeito à criança é assim compreendido:

\section{"[...] a internação de uma criança... tem que ser uma passagem boa, por mais que tenh a procedimentos dolo- rosos [...] não é fácil, eu sei que não é fácil, eu passei por isso, mas dá pra dar atenção, pra você ter paciência, você esperar um minuto, ele parar de se mexer mais, não ter que se- gurar ele com um pouquinho mais de força [...] eu acho que o crucial de uma internação para criança é uma passagem confortável e com muita paciência" (Naruto).}

\section{"Eu acho importante, a gente não esquecer que mesmo ela estando hospitalizada, ela ainda assim é uma criança [...]. Foi passado que tem que ser muito calma quando vai interagir com esse paciente, por- que como ele não compreende mui- to bem, a gente tem que entender e respeitar [...] que se a criança tá muito chorosa em tal momento, a gente espera um pouco, deixa ela se acalmar e volta em outro momen- to." (Gamora)}

Naruto afirma compreender a resistência da criança por ele próprio ter experienciado situação semelhante: "eu passei por isso". No entanto, o que se evidencia na fala dos dois estagiários é que aprenderam, com o que "Foi passado" para eles, que o profissional de saúde deve respeitar a criança porque ela "não compreende muito bem”. De modo que, em primeiro lugar, a criança é vista pelo lhe falta e não por suas potencialidades. Em segundo lugar, a possibilidade de "esperar um minuto", de voltar "em outro momento", para evitar segurar a criança "com um pouquinho mais de força” é uma visão centrada no profissional de saúde e não numa perspectiva mais positiva da criança no sentido de adotar uma atitude de mais interativa e de mais respeito. Essa visão positiva poderia evitar de ser deixa- do em segundo plano o direito da criança de se expressar sobre o(s) motivo(s) de sua resistência, do que ela sente, do que está sofrendo sob o impacto dos tratamentos. Dar a criança a possibilidade de se expressar permitiria tanto à criança, quanto ao profissional de saúde de agregarem conhecimentos: para o profissional, sobre a agentividade da criança, e para a criança, sobre práticas mais humanizadas de saúde. A ausência dessa interação dialógica termina por privá-los da construção de uma história comum, que servirá como ponto de partida para as próximas interações.

Outro ponto que se destaca nas análises dos estagiários é a percepção de Flecha, Hulk, da Mulher Elástica e de Pantera Negra com questôes legais a serem respeitadas pelas instituições hospitalares. De modo que nos processos de formação, tanto em Enfermagem e em Técnico de enfermagem, são os princípios legais que surgem como ponto capital na formação :

"O direito de recusa é o primeiro, né. Porque se a criança recusou e o familiar também recusou [como] mostrar o contrário? [...] Importante [...] que a gente saiba de alguns direitos principais e que o paciente também ou a mãe também conheça sobre essas leis, só pra gente não entrar em conflito $[. .$.$] tem que ficar atento às leis do$ ECA [...], ficar orientando sobre tudo, mas dependendo de um erro que ocorrer é pra gente ficar sempre muito atento. [...] a gente viu essa questão do ECA, mas era mais nos direitos e deveres do Estado.

Observa-se nessa narrativa coletiva que o conhecimento adquirido sobre os direitos da criança, durante o processo de formação formal, está centrado nos responsáveis pela criança, enquanto agentes centrais, sobre as decisões a serem tomadas e garantidas por Lei. Destaca-se a preocupação com "erros", "conflitos", "orientação", "direitos e deveres". Embora sejam aspectos de grande importância para o exercício ético da profissão, essa preocupação deixa de lado a concepção da criança como sujeito de direitos, o reconhecimento e valorização de sua fala e sobretudo do interesse de escutar atentamente o que a criança tem a dizer. Nesse sentido, no processo formação formal ou continua- 
da de enfermagem é de extrema importância abordar uma concepção atualizada da criança e das infâncias e explorar melhor com os futuros profissionais a importância da escuta sensível da criança hospitalizada para melhor se comunicar com ela. ${ }^{10}$

As análises, embora preliminares, levam a uma reflexão sobre a formação formal de futuros profissionais de enfermagem, que não apresentam com mais clareza as conquistas legais sobre os direitos da criança. Talvez por essa razão é que consideram algumas de suas atitudes como uma "concessão" de sua parte à criança ou como defesa $\mathrm{da}$ instituição. $\mathrm{O}$ que nos crucial ausente na formação dos entrevistados é a responsabilidade profissional diante do direito da criança de contar o que sentem, assim como é mais facilmente concedido ao paciente adulto o direito de se expressar. Sabemos, intuitivamente, mas também cientificamente, que ao narrar o que sentimos diante de uma experiência traumatizante ou reconfortante, podemos atribuir a essa experiência um novo sentido e compreender melhor o que sentimos, é nesse sentido que as narrativas da experiências vivida são autopoiéticas. ${ }^{11}$

\section{DISCUSSÃO}

Quando o adoecimento na criança exige hospitalização essa situação de isolamento e de confinamento tende a provocar um turbilhão de sentimentos e desencadear um trauma. ${ }^{13}$ Admite-se que a interação entre os profissionais e a criança, durante o processo de hospitalização, seria um atenuante importante para diminuir o impacto da internação. No entanto, as análises das entrevistas realizadas na pesquisa mostram que ainda é necessário maior aprofundamento de conhecimentos sobre a criança como um ser integral, ativo e criativo, por parte dos profissionais de saúde, para propiciar uma interação mais em pática com a criança hospitalizada. ${ }^{9}$

Outro aspecto que se sobressai das análises é o de incumbir unicamente aos pais a responsabilidade de transmitir aos profissionais de saúde os sentimentos da criança. Não se trata de excluir essa importante in- terlocução com pais ou cuidadores, o que emerge, no entanto, como questão central é que essa exclusividade tem duas consequências a serem consideradas. A primeira consequência é não possibilitar à criança o seu direito de narrar a própria experiência do adoecimento. A segunda consequência decorre da primeira, no sentido em que se entende que negar a criança essa possiblidade em uma situação de crise é também privá-la do entendimento que ela tem sobre si mesma e sobre que ela pode saber, fazer, ou não fazer, com o que está acontecendo em seu corpo e em sua vida. Se considerarmos o caso de crianças com doenças crônicas, que se hospitalizam com frequência, e muitas vezes desde a mais tenra idade, essa atitude contradiz a compreensão de que o ser humano se compreende interpretando o que lhe acontece. ${ }^{9}{ }^{14}$ Esses são princípios a serem levados em conta nos processos de humanização dos serviços de saúde, considerando-se os avanços das pesquisas realizadas com narrativas de crianças em que se revelam sua agentividade, sua capacidade de compreensão, a clareza de seu entendimento e insights importantes em seus diálogos. ${ }^{3}$

Não podemos esquecer que o reconhecimento dos direitos da criança a uma assistência humanizada, sugeridas pelos marcos legais, contou em larga medida com a atuação de profissionais de saúde na defesa de instituições hospitalares mais acolhedoras, sobretudo quando se trata de crianças que vivem parte de sua infância no hospital. Inclui-se aqui a criação de classes hospitalares para garantir o direito à continuidade dos processos de escolarização de crianças e adolescentes durante sua hospitalização para tratamento de saúde. ${ }^{15}$ Seguindo os mesmas princípios e diretrizes do ECA, a Lei $\mathrm{n}^{\circ} 8.242$ de 12 de outubro de 1991 criou o Conselho Nacional dos Direitos da Criança e do Adolescente (CONANDA), enquanto órgão colegiado, com atuação na promoção e defesa dos direitos da criança e adolescente. ${ }^{16}$ Logo depois, em 1995, a Sociedade Brasileira de Pediatria apresentou um texto elaborado sobre os Direitos da Criança e do Adolescente Hospitalizados, durante a $27^{a}$ Assembleia Ordinária do CONANDA, sendo aprovado pela Reso- lução $\mathrm{N}^{\circ} 41$, de 13 de outubro de $1995 .{ }^{17}$ Nesse sentido, em 1988, ou seja, há mais de 30 anos, várias associações europeias, reunidas em Leiden para a $1^{\text {a }}$ Conferência Europeia, consolidaram esses direitos na Carta Europeia das Crianças Hospitalizadas. ${ }^{17}$

Constatam-se portanto várias iniciativas legais que proclamar os direitos da criança, o que ainda falta é o reconhecimento desses direitos em diferentes esferas institucionais, incluindo-se a prática hospitalar cotidiana. ${ }^{9}{ }^{18}$

\section{CONCLUSÃO}

Concluímos em função das análises das entrevistas que nos foram concedidas pelos estagiários, que no processo de formação formal há uma lacuna sobre a qual precisamos refletir melhor, ou seja, o modo como se compreende a criança e seus direitos de se expressar sobre o que lhe diz respeito. Os cursos de formação em Enfermagem, seja no nível técnico ou superior, ao proporcionar ao futuro profissional uma compreensão sobre os benefícios de se narrar de forma crítica e reflexiva a experiência vivida, favoreceriam a esses futuros profissionais uma maior compreensão da dimensão autopoiética da autorreflexão e/ou da reflexão coletiva sobre as práticas de enfermagem.

Admitimos, finalmente, que se os estagiários tivessem a possibilidade de vivenciar positivamente essa experiência, ela favoreceria também uma maior compreensão do que significaria para a criança hospitalizada esse lugar de fala na interação, possibilitando-lhes, ao longo da formação, conhecer e reconhecer a importância da interação dialógica com a criança, compreendendo-a como agente social e sujeito de direitos e suas potencialidades nos processos de tratamento de saúde. 


\section{REFERÊNCIAS}

1. Barroso LMS. As idéias das crianças e adolescentes sobre seus direitos: um estudo evolutivo à luz da teoria piagetiana [Dissertação Mestrado]. Campinas (SP): Faculdade de Educação, Universidade Estadual de Campinas; 2000. 327p.

2. Brasil. Lei no 8.069, de 13 de julho de 1990. Dispõe sobre o Estatuto da Criança e do Adolescente e dá outras providências. Diário Oficial da República Federativa do Brasil, Brasília, DF, 16 jul. 1990.

3. Qvortrup J. Nove teses sobre a "infância como um fenômeno social". Pro-Posições [online]. 2011, v. 22, n. 1 [Acessado 16 Maio 2020], pp. 199-211. Disponível em: <https://doi. org/10.1590/S0103-73072011000100015>. Epub 13 Maio 2011. ISSN 1980-6248. https://doi.org/10.1590/S010373072011000100015.

4. Corsaro WA; Sociologia da infância. Ed. Penso; Edição 2. 2011. 5. Andrade DB da SF, Teibel ÉNH, Assunção AM de L. Análise sociogenética do núcleo central das representações sociais: investigações sobre o cuidado hospitalar de crianças. R. Educ. Public. [Internet]. $25^{\circ}$ de maio de 2020 [citado $27^{\circ}$ de Abril de 2021];29(jan/dez). Disponível em: https://periodicoscientificos. ufmt.br/ojs/index.php/educacaopublica/article/view/10294.

6. Depianti JRB, Melo LL, Ribeiro CA. Brincando para continuar a ser criança e libertar-se do confinamento da hospitalização em precaução. Esc. Anna Nery [Internet]. 2018 Rio de Janeiro, v.22, n.2. [citado $27^{\circ}$ de abril de 2020] Disponivel em: https://www. scielo.br/j/ean/a/jRdnC9jbDKJrLxw7TVpKbRx/?format=pdf\&lang=pt

7. Teixeira de Macedo Silva MC. Estratégias educacionais no ensino técnico em enfermagem durante a pandemia por COVID-19. SaudColetiv (Barueri) [Internet]. $10^{\circ}$ de maio de 2021 [citado $27^{\circ}$ de julho de 2021];11(64):5748-57. Disponível em: http://revistas.mpmcomunicacao.com.br/index.php/saudecoletiva/article/ view/1519

8. Jovchelovitch S, Bauer, MW. Entrevista Narrativa. In: BAUER, Martin W; GASKEL, George. Pesquisa qualitativa com texto, imagem e som. Trad. Pedrinho Guareschi, Petrópolis: Vozes, 2002. p. 90-113.

9. Passeggi MC, Rocha SM, Conti De, L. (Con)viver com o adoecimento: narrativas de crianças com doenças crônicas. [Internet]. Revista FAEEBA - Educação e contemporaneidade. 2016. maio/ ago; [Citado em 2020 Abr 25]; v.25, n.46, p. 45-57. Disponível em:https://www.revistas.uneb.br/index.php/faeeba/article/ view/2700/1829

10. Passeggi MC, Rocha SM. A pesquisa educacional com crianças: um estudo a partir de suas narrativas sobre o acolhimento em ambiente hospitalar. Revista edu questão [Internet]. $15^{\circ}$ de dezembro de 2012 [citado $28^{\circ}$ de março de 2020];44(30). Disponivel em: https://www.periodicos.ufrn.br/educacaoemquestao/article/view/4080

11. Passeggi MC. Narrar é humano! Autobiografar é um processo civilizatório. In: Passeggi MC, Da Silva VB, organizadoras. Invenções de vidas, compreensão de itinerários e alternativas de formação. São Paulo: Cultura Acadêmica, 2010. p. 103- 130.
12. Delory-Momberger, C. Fundamentos epistemológicos da pesquisa: biográfica em educação. Educação em Revista [online]. 2011, v. 27, n. 1 [Acessado 02 Maio 2020], pp. 333-346. Disponivel em: <https://doi.org/10.1590/S010246982011000100015>. Epub 01 Jun 2011. ISSN 1982-6621. https://doi.org/10.1590/S0102-46982011000100015.

13. Costa T, Morais A. A hospitalização infantil: vivência de crianças a partir de representações gráficas. Revista de Enfermagem UFPE on line [Internet]. 2016 Dez 15; [Citado em 2020 Mai 30]; 11(1): 358-367. Disponivel em: https://periodicos.ufpe.br/ revistas/revistaenfermagem/article/view/11916

14. Bruner J. Atos de significação. Trad. de Sandra Costa. Porto Alegre: Artes Médicas, 1997.

15. Rocha SM, Passeggi MC. Classe hospitalar: um espaço de vivências educativas para crianças e adolescentes em tratamento de saúde. [Internet]Revista @mbiente e educação. 2010. Jan./ Jul; [Citado em 2021 Jun 24]; v.2, n.1, p 113-121. Disponível em : https://publicacoes.unicid.edu.br/index.php/ambienteeducacao/ article/view/171

16. Gomes ILV, Caetano R, Jorge MSB. A criança e seus direitos na família e na sociedade: uma cartografia das leis e resoluções. Revista Brasileira de Enfermagem [online]. 2008, v. 61, n. 1 [Acessado 09 Abril 2020] , pp. 61-65. Disponível em: <https:// doi.org/10.1590/S0034-71672008000100009>. Epub 22 Fev 2008. ISSN 1984-0446. https://doi.org/10.1590/S003471672008000100009.

17. Brasil. Conselho Nacional de Defesa dos Direitos da Criança e Adolescente (BR). Resolução n 41, 13 de outubro de 1995. Dispõe sobre os direitos da criança hospitalizada. Diário Oficial da República Federativa do Brasil 1995 Out 17; Seção I:163.

18. Gomes ILV, Caetano R, Jorge MSB. Conhecimento dos profissionais de saúde sobre os direitos da criança hospitalizada: um estudo exploratório. Ciência \& Saúde Coletiva [online]. 2010, v. 15, n. 2 [Acessado 25 Março 2021] , pp. 463-470. Disponível em: <https://doi.org/10.1590/S1413-81232010000200023>. Epub 20 Abr 2010. ISSN 1678-4561. https://doi.org/10.1590/S141381232010000200023. 